\title{
The Research on the Application of Modern Mentoring System in Culinary Teaching
}

\author{
Lin Li \\ Jilin Agricultural Science and Technology university, jilin 132101, China \\ 735053339@qq.com
}

Keyword: Modern mentoring system ; Culinary teaching ; Academic system ; Teaching model

\begin{abstract}
The core of modern mentoring system emphasizes that "school - enterprise joint", "double teacher's training", "engineering change" and "position to become talent". After practising it, we can draw a conclusion that modern mentoring is a very practical in culinary teaching. The writer finds that in the process about exploring how to put the modern mentoring system in the culinary teaching which is not the best choice to only care about "double teachers training". "Double teacher training" means the teachers in school and business master .In addition to the school teachers and business master ,the score of the master can also be got from other ways . If we can enabled the senior students, we will get a better result . In fact, the academic model is not a new creation, but how to use and introduce it to the culinary teaching is a problem .This article is to explore the issue .
\end{abstract}

\section{The Origin of The Academic System}

In the early 15th century, British Eton College appeared the miniature of the academic system . The senior students manage and tutor primary level students. And now, the Eton Museum also hosts a student dormitory . It is used to show the academic system at that time .

After Eton College, many colleges and universities, begin to use academic system , especially Cambridge University. In this university, the senior students and junior students formed the "college family". The senior students were called "college dad "or "college mum ". In the college family, the senior students come from various majors. They are using one-on-one counseling and service for junior students .By cycling, a college family can become larger than ever before . And this "family" relationship will continue until after graduation and relationships between the "family members "are very strong .

The academic system of Universities of Leeds is also called "peer mentoring "project . The academic system of Universities of California is called "mentoring program ". Some American universities are also using academic system . The seniors are called "peer adviser "or "peer advising fellow". No matter how the colleges and universities are called academic system . All of the academic system from various universities have the same features . It means picking excellent students to serve the junior students . The service includes "life counseling" "study guidance "“emotion communication"

"values guidance "and others. It will help junior students join the campus life and receive the professional knowledge better .

\section{The Origin of Domestic Academic System}

The word "senior student" mainly comes from the academic system which is practicing by Kang Youwei . In 1891, Qing Guanxu eleven years, Kang set Wanmu School in Guangzhou . And it was the first one to practice academic system. In Wanmu School, the master chose excellent students to be senior. They were asked to solve the puzzles for junior students. Thus, it can be regarded as the origin of domestic modern academic system .

After that, the Republic of China, it was widely accepted by others. And it developed the senior student leading and helping junior student in equal and friendly emotion. And the seniors also officially evolved into lower grades of senior students . 
After the Republic of China, academic system is used and kept by Taiwan, Hong Kong and Macao .At the end of the last century, Hong Kong University of Science and Technology added some ideas into the academic system. It involved the graduates to make friends with college students who are in school. Meantime, it also opens the position to students. And the students could benefit a lot .

At the end of last century, there are dozes of colleges and universities began to practice academic system including Peking University, Sun Yat-sen University, Huazhong Normal University. And according to the domestic education, it added some creations to Hong Kong, Taiwan, Macao and foreign countries .

At this stage in the country, the academic system is widely accepted by many universities . And it develops into "freshman senior system "“dormitory academic system "Party membersacademic system" "learning tutor academic system" "peer apprenticeship" "alumni academic system" and so on . And these systems make a great effect on students management and study guidance .

\section{The Application Mode of Pedagogy in The Teaching Practice of Culinary}

Establish a Academic System Situation . It's essential to set a appropriate system scientifically that is the guarantee for a academic system works. It's not a simply process to establish a academic system . And it needs reasonable system to provide limitations and guarantees for various factors. In the process of using it, it needs to cooperate the connection among school, the major teachers ,seniors ,juniors and test place. It needs to practice in a formal way on selecting seniors .And it also requires the seniors about designing, planning, tutor time, and tutor place. And we also need to establish academic system. It will test the seniors and tutor juniors. All of these need formal and scientific system to finish and limit .

It's significant for any system to change idea. The core of the academic system is "self-management" "self-growth". If we want it to work well, we have the teachers and students received it . Meantime, we should also make it clear that academic system don't mean "baby sisters". The main task of the master of cooking is to lead the students who are assisted by the professional knowledge and practice the professional cooking skills. Thus, it requires the seniors to be excellent and has some professional quality. Studying hard is no longer an empty talk for both seniors and students. And assisted students become seniors soon or later. Because we establish the establish the assisting awareness ahead of time, it requires all of students to build a study idea which should be positive efforts .

The teacher's idea should be also changed. The students are not only to sit in classroom, but they have their own abilities and they can promote the professional skills by themselves. We should also give them some freedoms and open the laboratory. We should believe the effect of self-learning can't be ignored .

The concept of laboratory teachers should also be changed. The biggest difference between the cooking and other majors is that the required items have a certain risk. The "fire" and "knife" are dangerous for students. The traditional practice is to experiment with teachers instructors as long as the experimental class is a double insurance. They watch and manage students for fear that appears any dangers. In fact, it is meaningless . Our students are adults and they have a certain risk identification and keep safe. They are familiar to use "fire" and "knife". As long as the experimental teachers don't leave the position, to give some security, the other things can be handled by the students themselves, but also to cultivate students' awareness .

If we want to practice academic system, we have to create the environment. First, in order to make a learning team, the management level of the school should give some supports and in the student management to give some relaxation . Second, it needs some time to establish . It means giving students and assisted students a certain co-counseling training time. Expect for spare time, scheduling process should also be given some support. What's next, we should create a safe practice environment and improve the experimental conditions and facilities and equipment. To 
create a safe environment for students to learn independence and lower the dangerous factors . For example, in the laboratory there can be not exist flammable decoration materials and stoves should also use a safe device. Finally, we should create a good learning atmosphere for students .

Selecting Excellent Seniors. The seniors are responsible for the important duties of teaching guidance for junior students. So, not all the students are suitable for being "seniors". As for electing seniors, we should pay attention to selecting the student who is academic system skills and excellent professional skills. And according to the characteristics of the students, we should conduct a comprehensive inspection .

After selecting seniors, we should consider the issue about team cooperation, according to the students and the characteristics of the students assisted by the proportion of men and women in a comprehensive consideration after the combination of the team that can not be careless .

Pay Attention to Teaching Content. The academic system of culinary mainly uses "academic studying counseling" .The senior students and junior students form a teaching team and it is mainly completed by one to one. The senior's main mission is to teach professional knowledge and skill education. The seniors guide the assisted student to practice cooking skills. And they can explain the weaknesses.

The choice of teaching content is chosen by the students. And the seniors will tutor the weaknesses and unknown . But this choice is not entirely arbitrary and laissez-faire . First, both sides should clear the direction of counseling and it must be professional skills . Next, after tutoring, the seniors need to fill in the tutor reword. It will include the time, place, content and result. Thus, the instructor can inspect and understand the specific progress of students . Meantime, it will be easier to inspect the academic system in the final exam. It will accumulate the first-hand materials .

Strengthen the Students Management. Academic system is a learning team which is mainly learning professional skills . In practicing it, although we stress the importance about learning independence and managing themselves, we should also realize something we don't only relax student management but strengthen the student management. We relax the upper and lower boundaries of student management and time management. So that students can establish relationship with the seniors and they can have more non-classroom time. We should strengthen the management of this kind of emotional connection and stress the major function of the team . We can not let them use this relaxation to do things that have nothing to do with learning .

We measure the students' self-learning results through evaluation. So we should strengthen the evaluate management. We should put something into the students' comprehensive evaluation which is strictly executing regulations, filling in the tutor record and detection of teaching results .

The students' comprehensive evaluation are divided into two parts. One is evaluation of the tutor. The other is evaluating the assisted students' academic performance. Meantime, the assisted students' score should be related to the senior's

tutor evaluation. It's advisable to use a qualitative evaluation method for seniors. While the evaluation of the assisted students should use a quantitative comprehensive evaluation of the way more scientific and reasonable .

\section{The Meaning of The Academic System Implementation}

Comprehensive Training ,Full Incentive. The great significance of the academic system implementation of the student is to be able to effectively encourage all students . Under this learning system, the seniors and assisted students should work harder and more positive . As for assisted students, they will be seniors. They need to spare no efforts to study if they want to have the ability to teach junior students. And when it comes to seniors, they must have excellent professional knowledge and skills. Or they will lose face. And nobody wants to happen this situation. Thus, the seniors need to work harder so that they can have enough confidence to teach them .

Cultivate Autonomous Learning Ability. The core of the academic system is to cultivate students' autonomous learning ability. We can know that the team can choose the counseling 
content, time and place. And the teacher's blinding is dancing. It doesn't mean that the student's autonomy does not exist. On the contrary, under this system, the junior students are more willing to learn in case of the unknown needs. Under the learner's positive touch, the instructor can't refuse to learn directly prestige. Thus, we can build a learning atmosphere naturally and cultivate students' ability to learn independently. This is one of the academic system strengths

Effective Emotional Communication. There is an equal relationship between the seniors and the dependent students. They don't have so many boundaries between teachers and students. The assisted students can express themselves freely because they have the similar age and identity . They can become friends even relatives easily. This kind of effective emotional communication have them expertise the skills professional problems. They don't need to worry the teacher's preaching. It's good to their learning .

The Supplement of Modern Mentoring System. The modern mentoring system stress the importance of the master. Although the academic teacher and business master teach the students together, it's not enough for more and more students. What's more, the students can't ask the teachers or masters totally. But the academic system can make up it .

First, academic system stresses the one to one and one to many. It means the academic system can satisfy the student's needs from the numbers .

Second, the seniors can effectively communicate with the assisted students at every time. They can overcome the time, space, emotion and any letters .

Last, the seniors are also one of the "master" sources. Its essence can be attributed to the modern mentoring system .

Therefore, the master system can also be fully capable of as a modern mentoring system and the existence of a useful supplement .

\section{Conclusion}

In the course of concrete implementation, the academic system will inevitably encounter various problems such as the seniors lack experience and guidance or they make a team but they don't pay attention to learning and relaxing management. The seniors are biased by the junior students . These phenomena are normal. If we strengthen the managements and senior guidances, these problems can be avoided and prevented. It's proved that the meaning of academic system is far greater than its problem. It's an excellent teaching system which is worth exploring .

\section{Acknowledgements}

In this paper ,the research by Jilin Education Department, 2016, key research topic of vocational education and adult education reform, project approval number: 2016ZCZ017: Modern mentoring system construction to promote the development of applied cuisine specialty

\section{References}

[1] M.Wan: "Senior" colleges and universities pattern and effective sigh (MS.D., Jiangxi agricultural university, China 2011), p.57.

[2] Y.Yan.:Science and technology in western China,(2013)No.12..p156

[3] F.C.Meng:Journal of shijiazhuang economic school. (2014)No.4.p45.

[4] Y.Y. li: Small and medium-sized enterprise management and technology. (2014)No.1.p36. 